\title{
The Role of Preoperative Puborectal Muscle Function Assessed by Transperineal Ultrasound in Urinary Continence Outcomes at 3, 6, and 12 Months After Robotic-Assisted Radical Prostatectomy
}

\author{
Patricia Briar Neumann ${ }^{1}$, Michael O’Callaghan ${ }^{2-5}$ \\ ${ }^{1}$ School of Health Sciences, University of South Australia, Adelaide, Australia \\ ${ }^{2}$ Urology Unit, Flinders Medical Centre, Bedford Park, Australia \\ ${ }^{3}$ South Australian Prostate Cancer Clinical Outcomes Collaborative, Adelaide, Australia \\ ${ }^{4}$ Flinders Centre for Innovation in Cancer, Flinders University, Bedford Park, Australia \\ ${ }^{5}$ Freemasons Foundation Centre for Men's Health and Discipline of Medicine, University of Adelaide, Adelaide, Australia
}

Purpose: The efficacy of pelvic floor muscle training (PFMT) for men with postprostatectomy incontinence (PPI) after robotic-assisted radical prostatectomy (RARP) is controversial and the mechanism for its possible effect remains unclear. The aim of this study was to investigate the relationship between bladder neck $(\mathrm{BN})$ displacement, as a proxy for puborectal muscle activation, and continence outcomes after RARP.

Methods: Data were extracted from the South Australian Prostate Cancer Clinical Outcomes Collaborative database for men undergoing RARP by high volume surgeons who attended preoperative pelvic floor physiotherapy for pelvic floor muscle (PFM) training between 2012 and 2015. Instructions were to contract the PFM as if stopping the flow of urine. BN displacement was measured with 2-dimensional transperineal ultrasound, without digital rectal examination. Urinary continence status was assessed preoperatively and at 3, 6, and 12 months using the Expanded Prostate Cancer Index Composite 26. Data were analysed using logistic regression and mixed effects linear modelling. Confounding variables considered were baseline continence, age at diagnosis, margin status, nerve sparing procedures and pathological stage.

Results: Of 671 eligible men, 358 met the inclusion criteria and were available for analysis, with 136 complete datasets at 12-month follow-up. While BN movement was associated with preoperative continence, there was no significant effect of BN displacement on the change in urinary continence at 12 months postprostatectomy $(\mathrm{P}=0.81)$ or on the influence of time on continence over 3-12 months.

Conclusions: Continence outcomes were not associated with BN displacement, produced by activity of the puborectal portion of the levator ani muscle, at 3, 6, or 12 months after RARP. These results suggest that the puborectal muscle does not play a role in the recovery of continence after RARP and may help to explain the negative findings of many studies of PFMT for PPI.

Keywords: Pelvic floor; Prostatectomy; Urinary incontinence; Ultrasonography

- Grant/Fund Support: Data analysed as part of this manuscript was extracted from the South Australian Prostate Cancer Clinical Outcomes Collaborative (SA-PCCOC) Registry which has received funding from (in alphabetical order): Abbvie, AstraZeneca, Beat Cancer, Ferring Pharmaceuticals, Ipsen, Movember Foundation, The Hospital Research Foundation, Tolmar Australia and the Urological Society of Australia and New Zealand.

- Research Ethics: Ethics approval was granted to SA-PCCOC to collect data relating to prostate cancer including from patients in private practice, where this study was conducted and including all deidentified analyses for which prior patient consent had not specifically been obtained, as was the case for this analysis. Ethics approval was granted by the Southern Adelaide Human Research Ethics Committee (approval 307.14) and the study was conducted in accordance with the Helsinki Declaration.

- Conflict of Interest: No potential conflict of interest relevant to this article was reported.

Corresponding author: Patricia Briar Neumann

(iD) https://orcid.org/0000-0002-3066-5666

School of Health Sciences, University of South Australia, City East Campus, Adelaide 5000, Australia

E-mail: trish.neumann@unisa.edu.au / Tel: +61-8-413-940-246 / Fax: +61-8-8331-8989

Submitted: January 15, 2018 / Accepted after revision: April 2, 2018
This is an Open Access article distributed under the terms of the Cre(c)
commons.org/licenses/by-nc/4.0/) which permits unrestricted non-commercial use, distribution, and reproduction in any medium, provided the original work is properly cited. 


\section{INTRODUCTION}

Urinary incontinence remains a distressing complication for men after radical prostatectomy despite improvements in surgical techniques [1]. Pelvic floor muscle training (PFMT) is a commonly advocated treatment and is widely practiced. However the evidence for its efficacy is unclear, with systematic reviews and meta-analyses suggesting, at best, only limited short-term benefit [2-4].

The male continence mechanism is complex and the relative contribution of the different muscles in the pelvic floor to continence and postprostatectomy incontinence (PPI) has only recently begun to be elucidated [5-8]. Intervention studies on men with PPI have predominantly focused on training the levator ani muscle (LAM) but the lack of effect in many of these robust studies [9-12] suggests that the LAM may not be responsible for recovery of continence after radical surgery. One reason for the focus on LAM training has been the use of digital rectal examination (DRE) [13], a validated method providing ready access to the levator ani in men to allow clinical assessment of its function, based on similar assessment methods in women [14]. The urethral sphincter is the other key structure contributing to continence in the male $[15,16]$ but no comparable clinical assessment of urethral sphincter function has been described. DRE provides clinical information about the puborectal portion of the LAM, which can be palpated in the proximal half of the anal canal, contributing to its closure [17] and to elevation of the bladder neck (BN) [5]. In addition, it is common to teach men to contract the LAM, or provide biofeedback training, via the anus, with the proprioceptive input thus being from the anal or puborectal component of the LAM $[9-12,18,19]$. However, it is currently unclear to what extent the puborectal portion of the LAM contributes to recovery from PPI.

Two-dimensional transperineal ultrasound (2D-TPUS) is a newly validated and reliable method of assessing displacement of male pelvic structures, including the $\mathrm{BN}$, associated with contraction of the puborectal muscle [20]. Using this method, mean \pm standard deviation (SD) measures of $\mathrm{BN}$ displacement from $4.6 \pm 0.4$ to $20.6 \pm 0.1 \mathrm{~mm}$ have been reported in a cohort of men without prostate cancer [5], suggesting considerable variability in men's PFM function and motor control.

We hypothesized that there would be a positive association between postoperative continence and preoperative $\mathrm{BN}$ displacement and that this association would be strongest for $\mathrm{BN}$ displacement around the mean, representing activity of the puborectalis/levator ani muscle with normal resting tone and good motor control.

The aim of this study was therefore to investigate the relationship between BN displacement, measured with 2D-TPUS, as a proxy for puborectal muscle activity and men's continence status at 3,6, and 12 months after robotic-assisted radical prostatectomy (RARP).

\section{MATERIALS AND METHODS}

Demographic data and data on continence status were extracted from the South Australian Prostate Cancer Clinical Outcomes Collaborative (SA-PCCOC) database for analysis. Urinary continence status was assessed preoperatively and at 3, 6, 12 months using the Expanded Prostate Cancer Index Composite (EPIC)-26 [21]. Continence was assessed using the 'Urinary Incontinence' domain score of the EPIC-26 (questions $1-3,4 a)$. This score ranges from $0-100$, with 0 indicating complete lack of urinary continence and 100 indicating complete urinary continence. Response options for each EPIC item form a Likert scale, and multi-item scale scores are transformed linearly to a 0-100 scale, with higher scores representing better health-related quality of life.

Data on BN displacement were obtained prospectively during a routine 1-hour preoperative physiotherapy appointment in which men were given standardized education about the anatomy and function of the pelvic floor muscles, including the urethral sphincter mechanism, using a diagram of the male pelvic floor in sagittal section, a model pelvis and self-palpation of bony landmarks of the pelvis. Men were initially given standardized instructions in sitting and standing to contract their pelvic floor muscles as if stopping the flow of urine. They were instructed to be aware of retraction of the penis, elevation of the testicles towards the body and an awareness of the anal sphincter squeezing in, while maintaining a urethral focus of the action. Further feedback from the physiotherapist provided assistance to localise the action to the pelvic floor without global, especially upper abdominal muscle, activity and while breathing [22]. Puborectal muscle action was assessed by the physiotherapist, using 2D-TPUS to measure $\mathrm{BN}$ displacement, with the subject in a supine bent-knee position. A curved linear array ultrasound transducer (ultrasound system Mindray DP6600, Shenzhen Mindray Bio-Medical Electronics Co., Ltd., Shenzhen, China, 2009-2010) was covered with ultrasound gel, a 
plastic sheath and further ultrasound gel and placed on the perineum in the midsagittal plane to visualize the pubic tubercle anteriorly and the anorectal angle posteriorly, confirming midline position. The online callipers were used to identify the $\mathrm{BN}$ at rest and on maximum displacement during a voluntary contraction. Cranial displacement was considered to be correct and caudal displacement incorrect [14].

Displacement of the BN has been previously established as a valid measure of PFM activity in men. We used only the measure of the urethro-vesical junction, as described by Stafford et al. [23], to estimate changes in the position of the $\mathrm{BN}$ as a result of PFM activity.

Some practice and refinement of the action were permitted, with subjects using the ultrasound image for biofeedback. The maximum displacement measure was recorded in an electronic database for later analysis. DRE was only performed if pelvic floor muscle overactivity was suspected in the case of minimal excursion of the BN on 2D-TPUS or if the subject had poor proprioception. All TPUS measures were taken by one of three physiotherapists who had received training in the technique. 2DTPUS data analysis was conducted independently from those making ultrasound measurements.

All baseline measurements were made after the date of diagnosis and prior to RARP. Data were included from men who fulfilled the following patient profile/inclusion criteria:

- Robot-assisted laparoscopic radical prostatectomy performed by high volume surgeon ( $>50$ per year).

- Prostate cancer patients who underwent surgery between March 2012 and March 2016.

- Surgery was not performed post radiation therapy and there was no radiation therapy within 12 months of surgery.

- Patients had completed an EPIC 26 prior to surgery.

- A preoperative physiotherapy session in which $\mathrm{BN}$ displacement as a result of a PFM contraction was assessed using 2DTPUS.

Cases were excluded if they did not have complete data of BN displacement measured by RT TPUS or without a continence assessment before RALP or an EPIC-26 within 12 months of RALP.

\section{Data Analysis}

Data were analysed using logistic regression. Confounding variables considered were baseline continence, age at diagnosis, margin status, nerve sparing procedures, and pathological stage (Gleason grade: $\leq 6,7, \geq 8$; stage: $\leq \mathrm{T} 2, \geq \mathrm{T} 3$ ), body mass index and preoperative overactive bladder $(\mathrm{OAB})$. The presence of
$\mathrm{OAB} /$ benign prostatic hyperplasia was defined by positive responses to all 3 of the following questions on the EPIC-26 (Q31, weak urine stream or incomplete emptying; Q33, need to urinate frequently during the day; and Q34, overall, how big a problem has your urinary function been for you during the last 4 weeks?: response $0-5$, no problem-big problem?).

Logistic regression was used to investigate the relationship between baseline continence and $\mathrm{BN}$ displacement.

A mixed effects linear model was used to investigate the relationship between $\mathrm{BN}$ displacement and continence outcomes at 3,6 , and 12 months postsurgery. Any patient with at least one posttreatment outcome was included in this analysis.

Ethics approval was granted to SA-PCCOC to collect data relating to prostate cancer including from patients in private practice, where this study was conducted and including all deidentified analyses for which prior patient consent had not specifically been obtained, as was the case for this analysis. Ethics approval was granted by the Southern Adelaide Human Research Ethics Committee (approval 307.14) and the study was conducted in accordance with the Helsinki Declaration.

\section{RESULTS}

Six hundred seventy-one subjects were in the initial data set, with 358 subjects remaining after application of the inclusion/ exclusion criteria (Fig. 1). Reasons for exclusion were as follows: not high volume surgeon (10 subjects), surgery post radiation therapy or radiation therapy less than 12 months after surgery (4 subjects), no baseline EPIC-26 (64 subjects), no preoperative physiotherapy (2 subjects), no preoperative BN displacement measurement available (233 subjects).

Demographics of the cohort are presented in Table 1.

Overall, men in the cohort had an average age of 63 years at the time of diagnosis and had Gleason 6 cancer (46.7\%). Nerve sparing surgical procedures were reported in $27.3 \%$ of cases (14.2\% bilateral and $13.1 \%$ unilateral). Continence data was available for 47 men at 3 months postsurgery, 119 at 6 months and 136 men at 12 months (Fig. 1). Results of EPIC-26 urinary incontinence data for each time point are presented in Table 2.

\section{Baseline continence and bladder neck movement}

Overall, the mean urinary incontinence score in this cohort was 92.89 on the EPIC- 26 scale before surgery. Mean \pm SD of BN displacement was $9.72 \pm 4.36 \mathrm{~mm}$. Using logistic regression to assess continence (100\% vs. less than $100 \%$ ) against BN dis- 


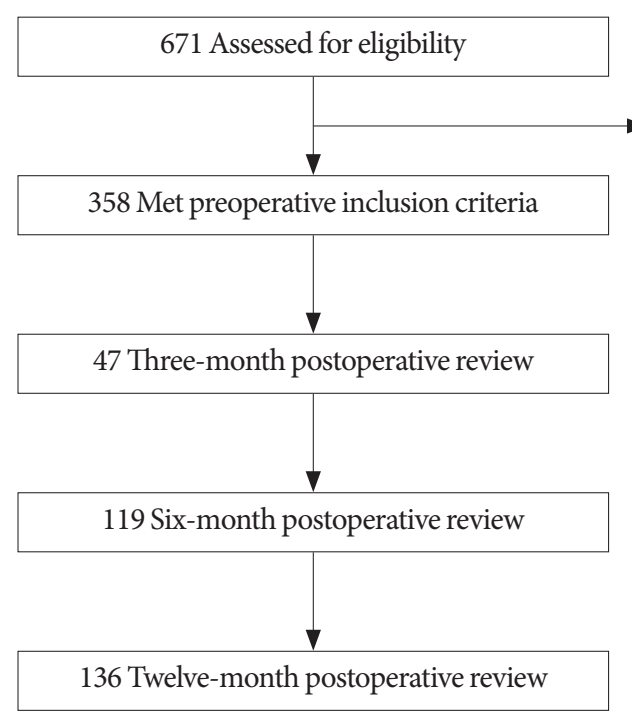

313 Excluded

10 Not high volume surgeon

4 Surgery post radiation therapy or radiation therapy less than 12 months after surgery 64 No baseline EPIC-26

2 No postoperative physiotherapy

233 No postoperative $\mathrm{BN}$ disptacement measurement available

Fig. 1. Flow chart of participants through the study. EPIC-26, Expanded Prostate Cancer Index Composite; BN, bladder neck.

Table 1. Demographics of study participants $(n=358)$

\begin{tabular}{|c|c|}
\hline Characteristic & Value \\
\hline Age at diagnosis (yr) & $63.89 \pm 6.06$ \\
\hline \multicolumn{2}{|l|}{ Gleason score at biopsy } \\
\hline$<7$ & $5(1.4)$ \\
\hline $3+4$ & $165(46.1)$ \\
\hline $4+3$ & $72(20.1)$ \\
\hline$>7$ & $46(12.8)$ \\
\hline Missing & $70(19.6)$ \\
\hline \multicolumn{2}{|l|}{ Pathology stage } \\
\hline 2 & $87(24.3)$ \\
\hline 3 & $200(55.9)$ \\
\hline Missing & $71(19.8)$ \\
\hline Positive cores at biopsy (\%) & $40.28 \pm 23.57$ \\
\hline \multicolumn{2}{|l|}{ Margin status } \\
\hline Clear & $212(59.2)$ \\
\hline Involved & $72(20.1)$ \\
\hline Missing & $74(20.7)$ \\
\hline \multicolumn{2}{|l|}{ Margin positive at apex } \\
\hline No & $247(69.0)$ \\
\hline Yes & $26(7.3)$ \\
\hline Missing & $85(23.7)$ \\
\hline \multicolumn{2}{|l|}{ Margin positive at bladder } \\
\hline No & $248(69.3)$ \\
\hline Yes & $24(6.7)$ \\
\hline Missing & $86(24.0)$ \\
\hline \multicolumn{2}{|l|}{ Neurovascular bundle sparing } \\
\hline No & $44(12.3)$ \\
\hline Bilateral & $51(14.2)$ \\
\hline Unilateral & $47(13.1)$ \\
\hline Missing & $216(60.3)$ \\
\hline
\end{tabular}

Values are presented as mean \pm standard deviation or number $(\%)$.
Table 2. EPIC-26 Urinary Incontinence Domain Scores (mean \pm SD) and number of subjects (\%) with complete EPIC-26 data at each time point

\begin{tabular}{lcc}
\hline EPIC-26 score $^{\mathrm{a})}$ & Mean \pm SD & No. $(\%)$ \\
\hline Baseline (all) & $92.88 \pm 13.84$ & $358(100)$ \\
Baseline (continent only) & 100 & $250(69.8)$ \\
3 Months & $60.79 \pm 25.74$ & $47(13.1)$ \\
6 Months & $76.79 \pm 22.89$ & $119(33.2)$ \\
12 Months & $79.44 \pm 21.59$ & $136(38.0)$ \\
Change in incontinence & $-13.90 \pm 21.21$ & - \\
$\quad$ score at 12 months & & \\
\hline
\end{tabular}

SD, standard deviation.

${ }^{a)}$ Expanded Prostate Cancer Index Composite (EPIC-26) Urinary Incontinence Domain Scores (questions 1-3, 4a).

placement, a positive association was observed (odds ratio [OR], 1.07; 95\% confidence interval [CI], 1.02-1.14; $\mathrm{P}=0.009)$ (Fig. 2).

\section{Continence postsurgery and bladder neck movement}

In this cohort of men, EPIC-26 Urinary Incontinence domain scores were typically lower 12 months after surgery compared with before surgery $(-13.9 \pm 21.21)$ (Table 2$)$. In univariable analysis, examining the effect of $\mathrm{BN}$ displacement on change in continence at 12 months postsurgery, no significant association was observed ( $\beta=0.30, P=0.46)$ (Fig. 3). Considering the change in continence over time (Fig. 4), a marked drop in continence was seen at the 3 months postsurgery time with partial 


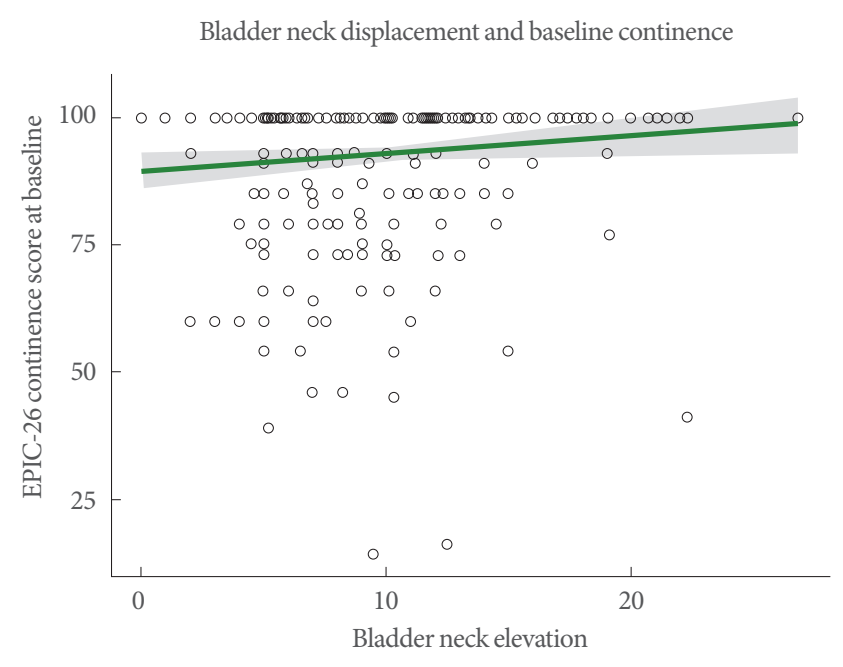

Fig. 2. Univariable analysis of bladder neck displacement and baseline continence $(n=358)$. EPIC-26, Expanded Prostate Cancer Index Composite.

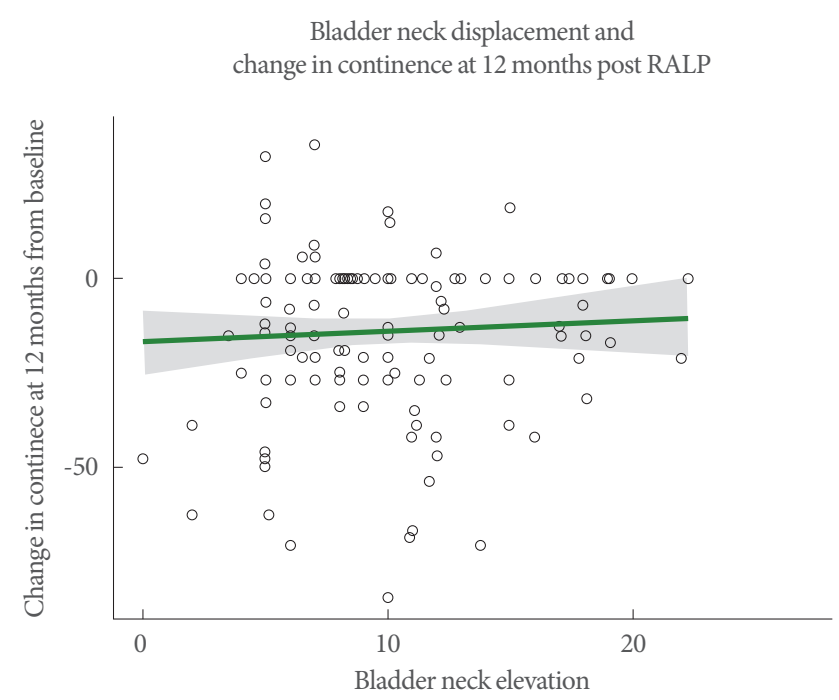

Fig. 3. Univariable analysis of bladder neck displacement and change in continence status at 12 months post RALP $(n=136)$. RALP, robotic-assisted laparoscopic prostatectomy.

recovery at 6 months. In mixed effects linear models, which examined continence from 3-12 months postsurgery, BN displacement was not significantly associated with change in continence in multivariable analysis including adjustment for age at diagnosis, surgical margin status, nerve sparing procedure status, pathology stage, presence of $\mathrm{OAB}$ at baseline and time $(\mathrm{P}=0.06)$. A representation of continence by quartile of $\mathrm{BN}$ movement shows this graphically (Fig. 5).

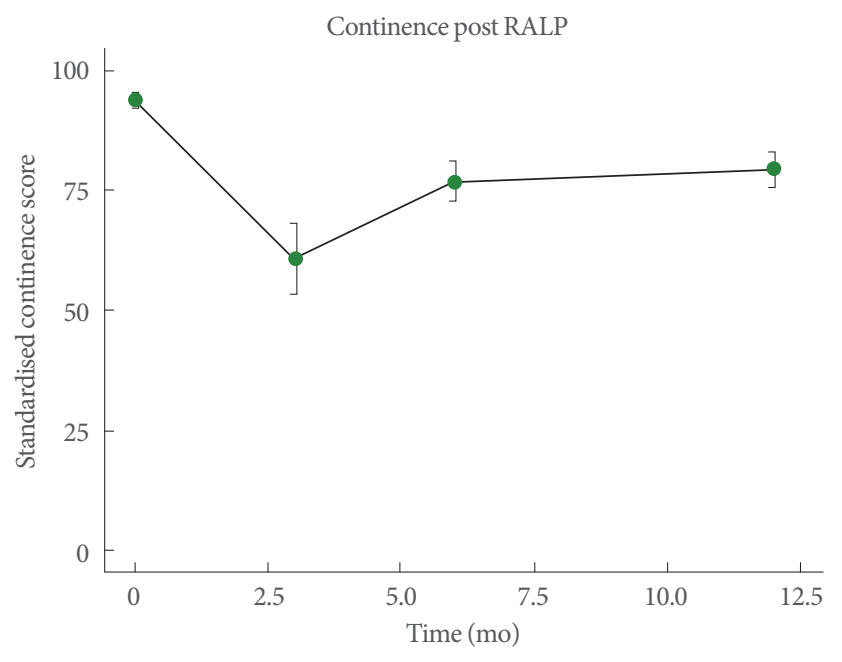

Fig. 4. Association of bladder neck displacement and continence at 3,6, and 12 months postsurgery using a mixed effects linear model. RALP, robotic-assisted laparoscopic prostatectomy.

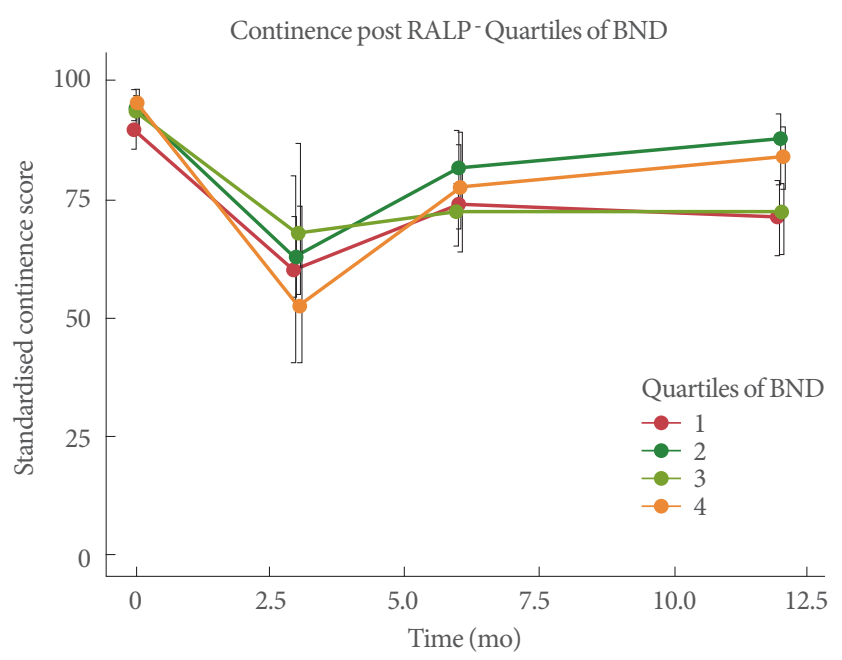

Fig. 5. Multivariable analysis showing association of quartiles of bladder neck displacement and continence at 3, 6, 12 months postsurgery. RALP, robotic-assisted laparoscopic prostatectomy; BND, bladder neck displacement.

\section{DISCUSSION}

The role of the LAM in the recovery of continence after radical prostate surgery is unclear. Our study investigated the role that men's ability to contract the puborectal portion of the LAM and elevate the $\mathrm{BN}$ before surgery might have on their continence status up to a year after a RARP. We used 2D-TPUS to assess movement of the $\mathrm{BN}$, indicative of activation of the puborectal muscle [5]. Our original hypothesis was not supported, as we 
found no association of preoperative $\mathrm{BN}$ displacement and urinary continence outcomes at any time from 3 to 12 months after surgery. Contrary to our hypotheses, $\mathrm{BN}$ displacement around the mean $(9.72 \mathrm{~mm})$, theoretically representing activity of the puborectal muscle/LAM with normal resting tone and good motor control, was not associated with superior continence outcomes. Furthermore, the lack of association remained when we examined quartiles of $\mathrm{BN}$ displacement in the regression analysis (Fig. 5). An explanation for the lack of association in the highest quartile ( 14-18 $\mathrm{mm}$ ) of BN displacement might be that the pelvic floor muscle had low resting tone, producing a large amplitude movement, with the potential for more BN mobility, which has been identified as a risk factor for postoperative UI $[24,25]$. Similarly, the lack of association with BN displacement in the lowest quartile $(\sim 0-4 \mathrm{~mm})$ could have been due to poor motor control, PFM weakness or on the other hand, due to high resting tone and limited ability to shorten the muscle fibres further. The lack of association between continence outcomes and any quartile of BN displacement might seem surprising as training of the PFM is so widely advocated. However, we suggest that it provides insights into the reasons why meta-analyses have failed to demonstrate efficacy [2-4].

We did find a small, statistically significant association between baseline $\mathrm{BN}$ elevation and baseline continence assessed by the continence domain of the EPIC-26 (OR, 1.07; 95\% CI, 1.02-1.14; $\mathrm{P}=0.014)$. We interpreted the ability to elevate the $\mathrm{BN}$ as a motor skill rather than as a reflection of PFM strength. This functional aspect of the PFM has not been investigated before in relation to continence outcomes and so comparisons with other studies are limited. Song et al. [26] used magnetic resonance imaging (MRI) to measure different aspects of the male pelvic muscles and found that thicker pelvic floor muscles preoperatively predicted better continence outcomes at 3 and 6 months after surgery. Sohn et al. [27] evaluated the anatomy of men preoperatively with MRI and found that men with a thicker puborectal muscle at the anorectal angle and more elevated $\mathrm{BN}$ regained continence earlier. These findings suggest that preoperative PFMT with a strength training protocol to hypertrophy the LAM might yield higher continence rates, but while Centemero et al. [28] found that 4 weeks of preoperative strength training produced earlier recovery of continence, others have failed to show an effect [9-12]. Cameron et al. [29] found no difference in LAM cross sectional area a year after surgery in continent and incontinent men, further clouding the role of the LAM in the recovery of continence.
The male continence mechanism is structurally complex $[5,15,16]$ and compromised urethral function has been implicated as a cause of PPI $[25,29,30]$. Furthermore, a recent study suggests that the puborectal muscle, together with the bulbocavernosus muscle, is unable to compensate for poor urethral function to improve continence outcomes [8]. The lack of association in the present study between BN displacement, as a proxy for puborectal muscle activation, and continence outcomes up to a year after surgery, provides further support for the theory that it is not the LAM but rather the urethral sphincter that is the key muscular structure responsible for the recovery of continence. Specific training to hypertrophy the voluntary component of the urethral sphincter could be a more effective target for muscle training but one study has found that intensive PFMT produced no improvement in postoperative urethral function, when assessed by urethral pressure profilometry during urodynamic studies [30].

There is a lack of standardization in PFMT in studies on PPI and the variable training protocols may account for some of the variation in the continence outcomes reported to date. It has been shown, for example, that different verbal commands produce different, measurable interactions between the puborectal, anal and urethral parts of the PFM, and with variations between individuals [7]. Some studies, which have focused on anal training with biofeedback, have had negative outcomes [912], while others with a more anterior/urethral focus, practising flow stopping and without anal biofeedback, have demonstrated a treatment effect $[28,31]$. We provided instructions to stop the flow of urine, focusing on the anterior PFM but men were also able to see the bladder neck on the ultrasound screen and focus on its elevation. At the time of data collection, we were not measuring displacement of the striated urethral sphincter [5], which may have produced significant associations with continence outcomes.

We used 2D-TPUS to evaluate the movement of the BN in this cohort of men. TPUS is a valid and reliable tool for assessing PFM activity in males and has advantages over DRE in being relatively noninvasive and providing real-time information about all the striated muscle components of the male pelvic floor, including the urethral sphincter [20]. It also has the advantage of providing visual feedback about the relevant activity of the PFM, without biasing the man's attention to the anal sphincter. The definition of the ultrasound image will depend, among other things, on the sophistication of the equipment used. We used a portable clinic ultrasound, which generally per- 
mitted good visualization and measurement of displacement of the BN from its position at rest and on contraction. The measures of $\mathrm{BN}$ displacement in the present study (mean $\pm \mathrm{SD}, 9.72$ \pm 4.38 ) were similar to those reported by Stafford et al. [5] (range, 4.6-20.6 mm). The similarity between this previous study and the present one lends credibility to our measures of $\mathrm{BN}$ movement.

We have not been able to visualize or measure activation of the striated urethral sphincter as easily as BN movement using 2D-TPUS in the clinic. Future research should investigate optimal methods to evaluate the activity of the urethral sphincter and whether specific training programs may be able to enhance its function and improve continence outcomes.

We did not routinely perform a DRE to assess action of the PFM in order to avoid providing anal biofeedback. However, in cases where there was minimal displacement of the $\mathrm{BN}$ on the ultrasound screen, the physiotherapist also performed a DRE to clarify the resting PFM tone and prescribe appropriate training e.g., PFM relaxation.

We have evaluated BN displacement after multimodal teaching of a correct contraction (i.e., pictures, models, self-palpation, clinician observation, and feedback). In all cases, we have reported positive values i.e., correct elevation of the $\mathrm{BN}$ and levator plate. Some of the missing TPUS data in excluded cases may have been due to difficulty obtaining a clear image and may have included cases with negative values i.e., incorrect action with levator ani depression.

A surprisingly high percentage (30\%) of men reported some incontinence preoperatively, according to the EPIC-26 (Table 2). From our methodology, it is not possible to identify the underlying cause of this baseline incontinence but one possible explanation is $\mathrm{OAB}$, which is a common cause of lower urinary tract symptoms in men [32] and with similar prevalence of $38 \%$ [33] and 21\% [34] reported in men before prostate surgery. When present preoperatively, $\mathrm{OAB}$ has been shown to predict poorer continence outcomes postprostatectomy [25,34]. Approximately one third of men reported symptoms of $\mathrm{OAB}$ at baseline, which we considered as a confounding variable in our analysis (Table 2). A further explanation may be preoperative terminal dribble (TD), which has been reported in $39.1 \%$ of men older than 40 years. In $27.2 \%$ of these men, TD was also objectively demonstrated [35].

A potential weakness of our study was some missing data for several confounding variables in the regression analyses. Nonetheless we have been able to report on a large cohort of men $(\mathrm{n}=136)$ for whom complete datasets were available for the 12-month analysis. Further strengths of this study are the use of a robust subjective measure of incontinence with the EPIC -26 [21] and valid and reliable measure of $\mathrm{BN}$ displacement using TPUS to assess PFM activity [20].

The lack of association between preoperative $\mathrm{BN}$ displacement, as a result of puborectal muscle contraction, and urinary incontinence up to 1 year after radical prostate surgery, provides an explanation for the lack of effect of some PFMT interventions for PPI that have focused on the anal sphincter and puborectal muscle activation. By targeting training of the striated urethral sphincter, rather than puborectal/LAM in men with PPI, it may be possible to improve continence outcomes post radical prostate surgery.

\section{ACKNOWLEDGEMENTS}

The authors thank the surgeons Dr. Peter Sutherland, Dr. Andrew Fuller, Dr. Richard Wells and Dr. John Bolt and the research team at South Australian Prostate Cancer Clinical Outcomes Collaborative for their invaluable contributions to the study.

\section{AUTHOR CONTRIBUTION STATEMENT}

- Full access to all the data in the study and takes responsibility for the integrity of the data and the accuracy of the data analysis: Michael O'Callaghan

-Study concept and design: Patricia Briar Neumann, Michael O'Callagham

- Acquisition of data: Patricia Briar Neumann

- Analysis and interpretation of data: Patricia Briar Neumann, Michael O'Callaghan

- Drafting of the manuscript: Patricia Briar Neumann

- Critical revision of the manuscript for important intellectual content: Patricia Briar Neumann

-Statistical analysis: Michael O'Callaghan

\section{REFERENCES}

1. Sanda MG, Dunn RL, Michalski J, Sandler HM, Northouse L, Hembroff L, et al. Quality of life and satisfaction with outcome among prostate-cancer survivors. N Engl J Med 2008;358:1250-61.

2. Wang W, Huang QM, Liu FP, Mao QQ. Effectiveness of preoperative pelvic floor muscle training for urinary incontinence after radi- 
cal prostatectomy: a meta-analysis. BMC Urol 2014;14:99.

3. Anderson CA, Omar MI, Campbell SE, Hunter KF, Cody JD, Glazener CM. Conservative management for postprostatectomy urinary incontinence. Cochrane Database Syst Rev 2015;1:CD001843.

4. Chang JI, Lam V, Patel MI. Preoperative pelvic floor muscle exercise and postprostatectomy incontinence: a systematic review and meta-analysis. Eur Urol 2016;69:460-7.

5. Stafford RE, Ashton-Miller JA, Constantinou CE, Hodges PW. Novel insight into the dynamics of male pelvic floor contractions through transperineal ultrasound imaging. J Urol 2012;188:122430.

6. Stafford RE, Ashton-Miller JA, Sapsford R, Hodges PW. Activation of the striated urethral sphincter to maintain continence during dynamic tasks in healthy men. Neurourol Urodyn 2012;31:36-43.

7. Stafford RE, Ashton-Miller JA, Constantinou C, Coughlin G, Lutton NJ, Hodges PW. Pattern of activation of pelvic floor muscles in men differs with verbal instructions. Neurourol Urodyn 2016;35:457-63.

8. Stafford RE, van den Hoorn W, Coughlin G, Hodges PW. Postprostatectomy incontinence is related to pelvic floor displacements observed with trans-perineal ultrasound imaging. Neurourol Urodyn 2017;37:658-65.

9. Geraerts I, Van Poppel H, Devoogdt N, Joniau S, Van Cleynenbreugel B, De Groef A, et al. Influence of preoperative and postoperative pelvic floor muscle training (PFMT) compared with postoperative PFMT on urinary incontinence after radical prostatectomy: a randomized controlled trial. Eur Urol 2013;64:766-72.

10. Dijkstra-Eshuis J, Van den Bos TW, Splinter R, Bevers RF, Zonneveld WC, Putter $\mathrm{H}$, et al. Effect of preoperative pelvic floor muscle therapy with biofeedback versus standard care on stress urinary incontinence and quality of life in men undergoing laparoscopic radical prostatectomy: a randomised control trial. Neurourol Urodyn 2015; 34:144-50.

11. Overgaard M, Angelsen A, Lydersen S, Mørkved S. Does physiotherapist-guided pelvic floor muscle training reduce urinary incontinence after radical prostatectomy? A randomised controlled trial. Eur Urol 2008;54:438-48.

12. Glazener C, Boachie C, Buckley B, Cochran C, Dorey G, Grant A, et al. Urinary incontinence in men after formal one-to-one pelvicfloor muscle training following radical prostatectomy or transurethral resection of the prostate (MAPS): two parallel randomised controlled trials. Lancet 2011;378:328-37.

13. Wyndaele JJ, Van Eetvelde B. Reproducibility of digital testing of the pelvic floor muscles in men. Arch Phys Med Rehabil 1996;77:117981.

14. Bø K, Sherburn M. Evaluation of female pelvic-floor muscle func- tion and strength. Phys Ther 2005;85:269-82.

15. Wallner C, Dabhoiwala NF, DeRuiter MC, Lamers WH. The anatomical components of urinary continence. Eur Urol 2009;55:93243.

16. Walz J, Burnett AL, Costello AJ, Eastham JA, Graefen M, Guillonneau $B$, et al. A critical analysis of the current knowledge of surgical anatomy related to optimization of cancer control and preservation of continence and erection in candidates for radical prostatectomy. Eur Urol 2010;57:179-92.

17. Liu J, Guaderrama N, Nager CW, Pretorius DH, Master S, Mittal RK. Functional correlates of anal canal anatomy: puborectalis muscle and anal canal pressure. Am J Gastroenterol 2006;101:1092-7.

18. Van Kampen M, De Weerdt W, Van Poppel H, De Ridder D, Feys H, Baert L, et al. Effect of pelvic-floor re-education on duration and degree of incontinence after radical prostatectomy: a randomised controlled trial. Lancet 2000;355:98-102.

19. Laurienzo CE, Sacomani CA, Rodrigues TR, Zequi Sde C, Guimar e GC, Lopes A. Results of preoperative electrical stimulation of pelvic floor muscles in the continence status following radical retropubic prostatectomy. Int Braz J Urol 2013;39:182-8.

20. Stafford RE, Ashton-Miller JA, Constantinou CE, Hodges PW. A new method to quantify male pelvic floor displacement from $2 \mathrm{D}$ transperineal ultrasound images. Urology 2013;81:685-9.

21. Szymanski KM, Wei JT, Dunn RL, Sanda MG. Development and validation of an abbreviated version of the expanded prostate cancer index composite instrument for measuring health-related quality of life among prostate cancer survivors. Urology 2010;76:124550.

22. Thompson JA, O'Sullivan PB, Briffa NK, Neumann P. Differences in muscle activation patterns during pelvic floor muscle contraction and Valsalva maneuver. Neurourol Urodyn 2006;25:148-55.

23. Stafford RE, Coughlin G, Lutton NJ, Hodges PW. Validity of estimation of pelvic floor muscle activity from transperineal ultrasound imaging in men. PLoS One 2015;10:e0144342.

24. Kirschner-Hermanns R, Najjari L, Brehmer B, Blum R, Zeuch V, Maass N, et al. Two- and three-/four dimensional perineal ultrasonography in men with urinary incontinence after radical prostatectomy. BJU Int 2012;109:46-51.

25. Heesakkers J, Farag F, Bauer RM, Sandhu J, De Ridder D, Stenzl A. Pathophysiology and contributing factors in postprostatectomy incontinence: a review. Eur Urol 2017;71:936-44.

26. Song C, Doo CK, Hong JH, Choo MS, Kim CS, Ahn H. Relationship between the integrity of the pelvic floor muscles and early recovery of continence after radical prostatectomy. J Urol 2007;178:208-11.

27. Sohn DW, Hong CK, Chung DJ, Kim SH, Kim SJ, Chung J, et al. 
Pelvic floor musculature and bladder neck changes before and after continence recovery after radical prostatectomy in pelvic MRI. J Magn Reson Imaging 2014;39:1431-5.

28. Centemero A, Rigatti L, Giraudo D, Lazzeri M, Lughezzani G, Zugna D, et al. Preoperative pelvic floor muscle exercise for early continence after radical prostatectomy: a randomised controlled study. Eur Urol 2010;57:1039-43.

29. Cameron AP, Suskind AM, Neer C, Hussain H, Montgomery J, Latini JM, et al. Functional and anatomical differences between continent and incontinent men post radical prostatectomy on urodynamics and 3T MRI: a pilot study. Neurourol Urodyn 2015;34:527-32.

30. Dubbelman YD, Groen J, Wildhagen MF, Rikken B, Bosch JL. Urodynamic quantification of decrease in sphincter function after radical prostatectomy: relation to postoperative continence status and the effect of intensive pelvic floor muscle exercises. Neurourol Urodyn 2012;31:646-51.

31. Burgio KL, Goode PS, Urban DA, Umlauf MG, Locher JL, Bueschen A, et al. Preoperative biofeedback assisted behavioral train- ing to decrease post-prostatectomy incontinence: a randomized, controlled trial. J Urol 2006;175:196-201.

32. Chung E, Katz DJ, Love C. Adult male stress and urge urinary incontinence - a review of pathophysiology and treatment strategies for voiding dysfunction in men. Aust Fam Physician 2017;46:6616.

33. Song C, Lee J, Hong JH, Choo MS, Kim CS, Ahn H. Urodynamic interpretation of changing bladder function and voiding pattern after radical prostatectomy: a long-term follow-up. BJU Int 2010; 106:681-6.

34. Yamada Y, Fujimura T, Fukuhara H, Sugihara T, Miyazaki H, Nakagawa T, et al. Overactive bladder is a negative predictor of achieving continence after robot-assisted radical prostatectomy. Int J Urol 2017;24:749-56.

35. Kim JH, Shim JS, Choi H, Moon DG, Lee JG, Kim JJ, et al. Terminal dribbling in male patients with lower urinary tract symptoms: relationship with International Prostate Symptom Score and with intravesical prostatic protrusion. BMC Urology 2015;15:89. 